\title{
Chordoma: a systematic review of the epidemiology and clinical prognostic factors predicting progression-free and overall survival
}

\author{
S. H. Bakker ${ }^{1}$ - W. C. H. Jacobs ${ }^{1}$ - W. Pondaag ${ }^{1}$ - H. Gelderblom ${ }^{2}$ - R. A. Nout ${ }^{3}$ · P. D. S. Dijkstra ${ }^{4}$ - W. C. Peul ${ }^{1}$. \\ C. L. A. Vleggeert-Lankamp ${ }^{1}$
}

Received: 3 December 2017 / Revised: 3 September 2018 / Accepted: 8 September 2018 / Published online: 15 September 2018

(c) The Author(s) 2018

\begin{abstract}
Background and aims The aim of this systematic review is to describe the epidemiology of chordoma and to provide a clear overview of clinical prognostic factors predicting progression-free and overall survival.

Methods Four databases of medical literature were searched. Separate searches were performed for each of the two objectives. Reference and citation tracking was performed. Papers were processed by two independent reviewers according to a protocol that included risk of bias analysis. Disagreement was resolved by discussion. Pooled analyses were planned if homogeneity of data would allow.

Results Incidence-incidence rates ranged between 0.18 and 0.84 per million persons per year and varied between countries and presumably between races. On average patients were diagnosed in their late fifties and gender data indicate clear male predominance. Two of the largest studies $(n=400$ and $n=544)$ reported different anatomical distributions: one reporting the skull base and sacrococcygeal area affected in $32 \%$ and $29 \%$ of cases, whereas the other reporting that they were affected in $26 \%$ and $45 \%$ of cases, respectively.

Prognostic factors Statistically significant adverse prognostic factors predicting progression-free and overall survival include female sex, older age, bigger tumour size, increasing extent of tumour invasion, non-total resection, presence of metastasis, local recurrence, and dedifferentiated histological subtype.

Conclusions Incidence rate and anatomical distribution vary between countries and presumably between races. Most chordomas arise in the skull base and sacrococcygeal spine, and the tumour shows clear male predominance. Multiple adverse prognostic factors predicting progression-free and overall survival were identified in subgroups of patients.
\end{abstract}

Graphical abstract These slides can be retrieved under Electronic Supplementary Material.
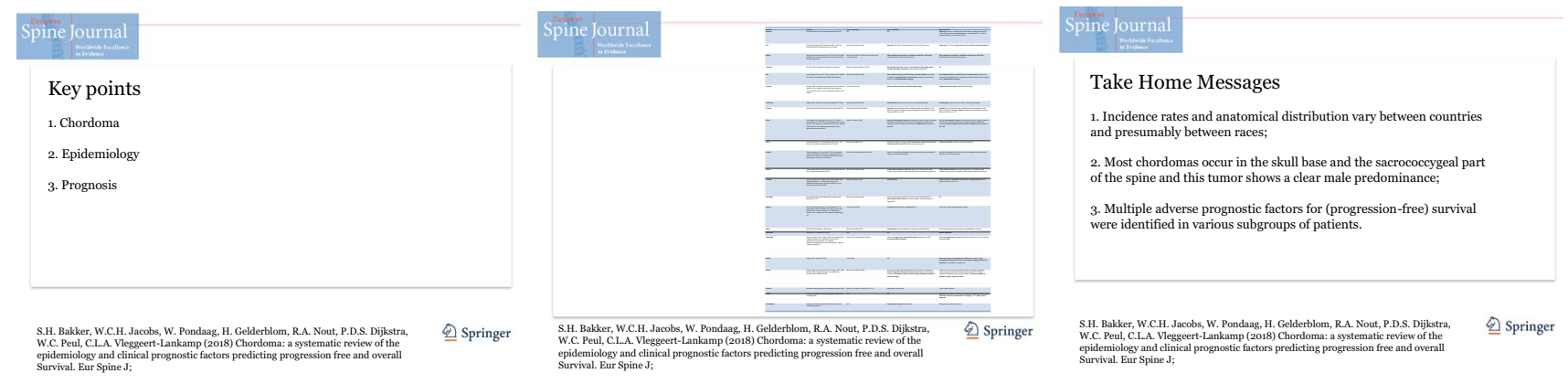

Electronic supplementary material The online version of this article (https://doi.org/10.1007/s00586-018-5764-0) contains supplementary material, which is available to authorized users.

Extended author information available on the last page of the article 
Keywords Chordoma $\cdot$ Epidemiology $\cdot$ Prognosis $\cdot$ Survival $\cdot$ Systematic review

\section{Introduction}

Chordoma is the most common primary malignant bone tumour of the spine and also frequently affects the skull base $[1,2]$. They are thought to arise from remnants of the embryonal notochord and were first described by Virchow in 1857 , who mistakenly thought the tissue was softened cartilage with hydropic degeneration of cells and hence coined the term ecchondrosis physaliphora [3]. Müller [4] was first to suggest in 1858 that these tumours may be of notochordal origin. In humans, most notochordal remnants disappear during the first years of life [5]. By a mechanism still unknown, in some people notochordal tissue remains along the axial skeleton, which explains the locations where chordoma occurs: the bulk arises at the sacrum or clivus and the remainder occur at varying levels of the mobile spine. However, not every remnant of notochord transforms into chordoma. Sometimes the tissue develops into a benign notochordal cell tumour, and the majority of these are harmless [6]. The mechanism by which some remnants transform into malignant tissue remains largely unclear, but some genetic alterations, most importantly in the brachyury gene, have been associated with chordoma [7]. Chordoma is considered a low-to-intermediate grade, slow-growing sarcoma, which may lead to the false belief that they are relatively benign tumours. Because of their propensity to grow in a destructive and invasive way, radical resection is challenging — even for the experienced surgeon-and is often not possible without causing morbidity or even mortality. Additionally, these tumours are fairly resistant to radiation therapy and systemic therapy. For this reason, a lot of effort is put into developing effective forms of adjuvant therapy, mainly in the shape of high-dose radiation therapy (protons and carbon ions) and chemotherapy. Research also focuses on identifying prognostic factors predicting outcome of treatment. Based on such factors, physicians can alter treatment plans and counsel patients. In recent years, many papers describing an abundance of prognostic factors were published, but to this day, no overview has been provided.

In addition to this, there is an ongoing controversy about epidemiology of chordoma. The debate focuses on the incidence rate of chordoma and which part of the axial skeleton is most frequently affected. This is a significant question, since treatment of skull base chordoma and chordoma of the spine differs in important ways (e.g. extralesional vs. intralesional resection) and patients suffer different symptoms and signs depending on the location and treatment of the tumour. The goal of this systematic review is to accurately describe the epidemiology of chordoma and to provide a clear overview of clinical prognostic factors predicting progression-free survival (PFS) and overall survival (OS). In doing so, it aims to facilitate decision-making, improve patient counselling, and guide future research. Special attention is paid to the increasingly important role of radiation therapy.

The second part of this systematic review, to be published later, will investigate the long-term outcome of (combined) treatment strategies for chordoma.

\section{Methods}

In order to provide a complete, objective, and easily reproducible review of the current literature, a protocol was designed before the literature search was conducted. The protocol specified the aims of the systematic review, the search strategy, the selection criteria, the process of risk of bias assessment, and guidelines for the extraction and synthesis of data.

\section{Search strategy}

With the aid of a health care librarian specialised in literature research, a sensitive search strategy was composed for PubMed, Embase, Web of Science, and the Cochrane Library. A search string for the target patient population was separately combined with a search string for epidemiological studies and a search string for studies on prognostic factors for PFS and OS. In order not to limit search results, no search strings were used for therapy and outcome. Additionally, reference and citation tracking was performed on included papers. To further increase the reach of the search strategy, a search string for (systematic) reviews and meta-analyses was made. The reference lists of the papers identified through this search string were planned to be searched for original papers that met inclusion criteria and were not yet identified through the aforementioned searches. The search was conducted in October 2016. The full search strategies can be found in supplementary material.

\section{Selection criteria—epidemiological papers}

Papers had to be population-based cohort studies, registering all incident cases of histologically proven chordoma, and had to be written in English, German, French, or Dutch. The country or region under study and details of the population under surveillance had to be described, as well as the method of case collection. Papers not reporting incidence number were excluded. 


\section{Selection criteria-prognostic papers}

Papers could be either prospective or retrospective, and their goal had to be to assess clinical prognostic factors predicting PFS, OS, or both. Patients had to have histologically proven chordoma. Papers were excluded when selection of patients was performed based on age or gender or when patient cohorts overlapped with those of a more recently published paper. In addition, papers excluding patients lost to followup without proper cause and explanation were excluded. At least 20 consecutive patients had to be included, and the paper had to be written in English, German, French, or Dutch. Papers published before 1990 were not considered for inclusion.

The selection process was carried out independently by two reviewers (SB and $\mathrm{WJ}$ ). When the abstract provided insufficient information, the full text article was assessed. When disagreement arose, a third reviewer (CVL) made the final decision about inclusion.

\section{Risk of bias assessment}

Risk of bias assessment was conducted separately for the epidemiological and the prognostic papers included in this review. For epidemiological papers, the checklist developed by Hoy et al. [8] was used. For prognostic papers, the checklist by Hayden et al. [9] was used. Both checklists were validated previously and provide summary scores. Risk of bias assessment was carried out independently by two reviewers (SB and CVL). When discussion failed to resolve disagreement, a third reviewer (WJ) made the final decision about inclusion.

\section{Data extraction and synthesis}

Prior to data extraction, forms were drafted onto which data were to be collected. Subsequently, data were extracted by one reviewer (SB) and checked for mistakes by another (WJ). For epidemiological studies, data on the country under study, the time period under investigation, tumour location, and patient demographics were collected. For prognostic studies, data on treatment, patient demographics, duration of follow-up, and clinical prognostic factors were collected. Pooled analyses were planned to be performed if homogeneity of data would allow.

\section{Results}

\section{Epidemiology}

\section{Literature search}

Through the literature search, a total of 1383 citations were identified. After the removal of duplicates, 963 original citations remained (Fig. 1). The selection procedure further narrowed the number of papers down to 6 that met all criteria for inclusion [10-15]. Reference and citation tracking resulted in one additional paper that was included [16]. Checking the reference lists of (systematic) reviews and meta-analyses failed to identify new papers. This brought the total number of included papers to 7 . An overview of study characteristics is provided in Table 1 . The decision was made to include both studies from the USA, regardless of their overlapping time periods, because the study by Smoll et al. [12] spans a longer time period, but does not report the anatomical distribution of the tumour.

\section{Risk of bias assessment}

Consensus about risk of bias scores was reached for all studies. All studies were concluded to have a low risk of bias. The study with the highest risk of bias still had a summary score of 7 out of 10 points [14]. Table 2 provides an overview of risk of bias assessment.

\section{Overview}

All studies were population-based cohort studies and were published in English between 1976 and 2013. An overview of the extracted data is given in Table 3. The data on incidence all originate from nation- or statewide registries, located in several European countries, the USA, and Taiwan. For all registries histological confirmation of the diagnosis was required. The three largest studies used the SEER database in the USA and the National Cancer Data Repository and the Office of National Statistics in England, with case numbers ranging from 400 to 1062 [10-12]. Incidence rates ranged from 0.18 to 0.84 per million persons per year and varied per country.

The most striking difference in incidence rates was observed comparing the English study, which reports an incidence of 0.3-0.4 cases per million inhabitants per year with the largest US study, which reports an incidence rate of 0.84 cases per million persons per year [11, 12]. The data used by the English study were more similar to the incidence rates observed for the other European countries and the incidence rate reported for the Taiwanese study, varying from 


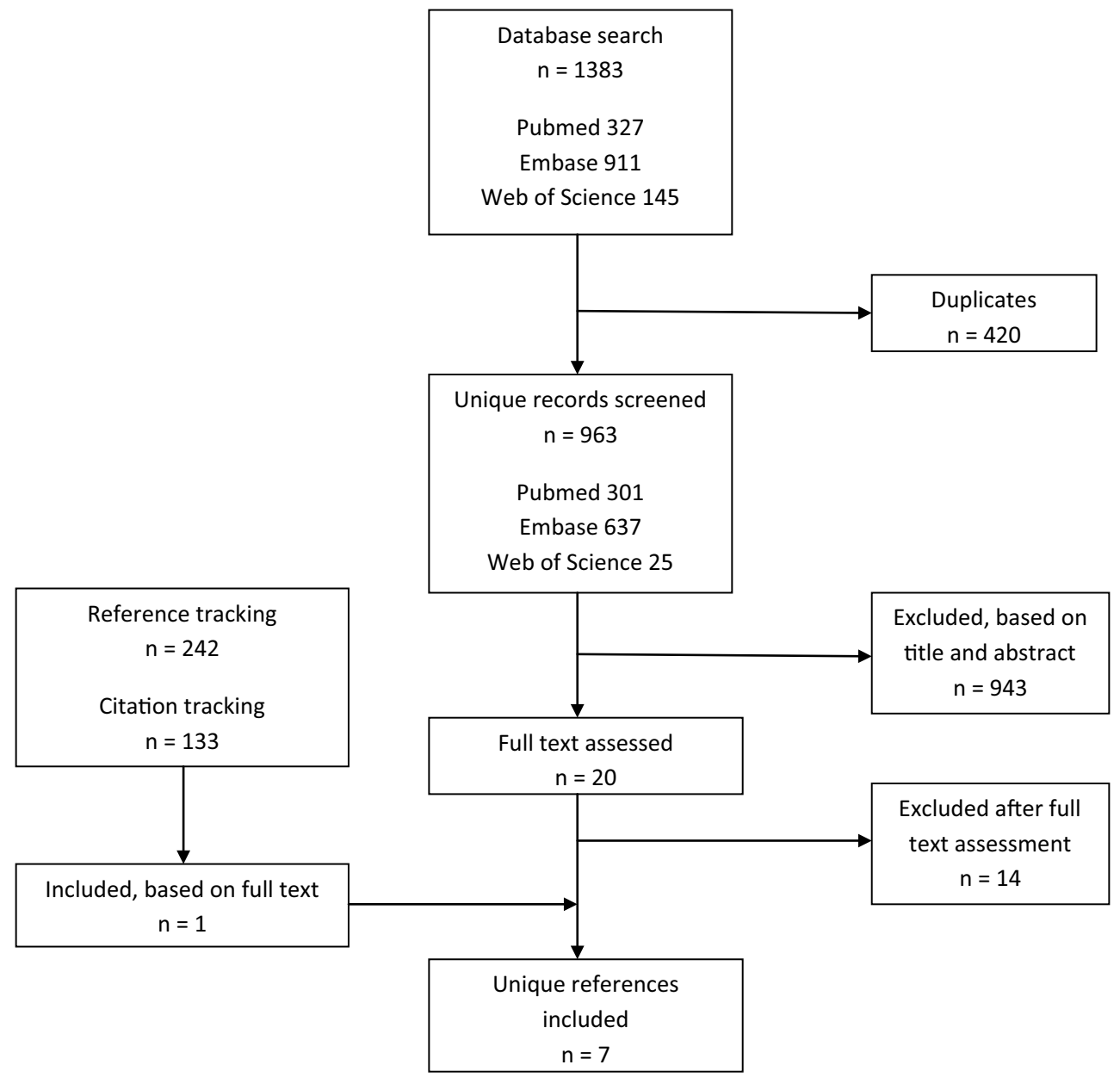

Fig. 1 Flowchart-epidemiology

Table 1 Risk of bias-epidemiology

$\begin{array}{llllll}\text { McMaster Whelan Smoll Stiller Eriksson } & \text { Hung } & \text { Pavolainen }\end{array}$

External validity

Close representation of national population

Sampling frame true to or close to target population

Random selection or census undertaken

Likelihood of non-response bias minimalised

Internal validity

Data collected directly from subjects

Acceptable case definition

Reliable and valid measurement of parameters

Same mode of data collection for all subjects

Appropriate length of incidence period

Appropriate numerator and denominator

Summary score

$\begin{array}{lllllll}+ & + & + & + & + & + & + \\ + & + & + & + & + & + & + \\ + & + & + & + & + & + & + \\ + & + & + & + & + & - & + \\ & & & & & & \\ + & + & + & + & + & + & + \\ + & + & + & + & + & + & + \\ + & + & + & + & + & - & + \\ + & + & + & + & + & + & - \\ + & + & + & + & + & + & + \\ + & + & + & + & - & - & - \\ 10 / 10 & 10 / 10 & 10 / 10 & 10 / 10 & 9 / 10 & 7 / 10 & 8 / 10\end{array}$

0.18 to 0.52 per million persons per year and the incidence rate of $<1$ per million per year for the Europe-wide study [13-16].
On average, patients were diagnosed in their late fifties and gender data indicated a clear male predominance. Studies reported different anatomical distributions, again 
Table 2 Study characteristics-epidemiology

\begin{tabular}{|c|c|c|c|c|c|c|}
\hline Authors & $\begin{array}{l}\text { Year of } \\
\text { publica- } \\
\text { tion }\end{array}$ & Study quality & Country or region & Time period & Registry & Case definition \\
\hline McMaster & 2001 & $10 / 10$ & USA & $1973-1995$ & $\begin{array}{l}\text { Surveillance, Epidemiology, and End Results } \\
\text { programme }\end{array}$ & ICD-O-2 9370/3 \\
\hline Whelan & 2012 & $10 / 10$ & England & 1979-2007 & $\begin{array}{l}\text { National Cancer Data Repository and the Office of } \\
\text { National Statistics }\end{array}$ & ICD-O M937 \\
\hline Smoll & 2013 & $10 / 10$ & USA & 1973-2009 & $\begin{array}{l}\text { Surveillance, Epidemiology, and End Results } \\
\text { programme }\end{array}$ & ICD-O-3 9370/3 \\
\hline Stiller & 2013 & $10 / 10$ & Europe & 1995-2002 & $\begin{array}{l}\text { RARECARE project, using } 64 \text { cancer registries } \\
\text { across Europe }\end{array}$ & ICD-O-39370 \\
\hline Eriksson & 1981 & $9 / 10$ & Sweden & $1958-1970$ & Swedish Cancer Registry & Histology \\
\hline Hung & 2014 & $7 / 10$ & Taiwan & 2003-2010 & Taiwan Cancer Registry & ICD-O-3 \\
\hline Paavolainen & 1976 & $5 / 10$ & Finland & $1953-1971$ & Finnish Cancer Registry & Histology \\
\hline
\end{tabular}

Table 3 Extracted data-epidemiology

\begin{tabular}{|c|c|c|c|c|c|c|}
\hline Authors & Number of cases & $\begin{array}{l}\text { Incidence rate } / 10^{6} \% \\
\text { year }\end{array}$ & Age & Gender & $\begin{array}{l}\text { Anatomical distribu- } \\
\text { tion }\end{array}$ & Study quality \\
\hline McMaster & 400 & 0.80 & $\begin{array}{l}\text { Median 58.5 } \\
\text { (range 3-95) }\end{array}$ & $\begin{array}{l}\text { M: } 1.0 / 10^{6} \\
\text { F: } 0.6 / 10^{6}(p=0.0002)\end{array}$ & $\begin{array}{l}\text { SB: } 32 \% \\
\text { MS: } 32.8 \% \\
\text { SC: } 29.2 \% \\
\text { Other: } 6.0 \%\end{array}$ & $10 / 10$ \\
\hline Whelan & 544 & $\begin{array}{l}\text { 1979-1987: } 0.3 \\
\text { 1988-1997: } 0.3 \\
\text { 1998-2007: } 0.4\end{array}$ & NR & NR & $\begin{array}{l}\text { SB: } 26 \% \\
\text { MS: } 23 \% \\
\text { SC: } 45 \% \\
\text { Missing: } 6 \%\end{array}$ & $10 / 10$ \\
\hline Smoll & 1062 & 0.84 & $\begin{array}{l}\text { Median } 58 \text { (interquar- } \\
\text { tile range } 29 \text { years) }\end{array}$ & $\begin{array}{l}\text { M: } 1.06 / 10^{6} \\
\text { F: } 0.66 / 10^{6}\end{array}$ & NR & $10 / 10$ \\
\hline Stiller & 352 & $<1$ & $\begin{array}{l}0-14:<0.1 / 10^{5} \\
15-24:<0.1 / 10^{5} \\
25-64:<0.1 / 10^{5} \\
65+: 0.1 / 10^{5}\end{array}$ & $\begin{array}{l}\text { M: } 1 / 10^{6} \\
\text { F: }<1 / 10^{6}\end{array}$ & NR & $10 / 10$ \\
\hline Eriksson & 51 & 0.51 & Mean 57 (range 6-87) & $\begin{array}{l}\text { M: } 51 \% \\
\text { F: } 49 \%\end{array}$ & $\begin{array}{l}\text { SB: } 27 \% \\
\text { MS: } 16 \% \\
\text { SC: } 57 \%\end{array}$ & $9 / 10$ \\
\hline Hung & 83 & $\begin{array}{l}0.40 \\
\text { M: } 0.52(0.38-0.66) \\
\text { F: } 0.25(0.15-0.35)\end{array}$ & $\begin{array}{l}0-24: 6 \\
25-59: 48 \\
\geq 60: 29\end{array}$ & $\begin{array}{l}\text { M: } 67 \% \\
\text { F: } 33 \%\end{array}$ & NR & $7 / 10$ \\
\hline \multirow[t]{2}{*}{ Paavolainen } & 20 & M: 0.30 & $\begin{array}{l}\text { Mean } 55.5 \text { (youngest } \\
\text { patient in 0-9 group, } \\
\text { oldest in } 70-79 \text { ) }\end{array}$ & M: $60 \%$ & SB: $10 \%$ & $5 / 10$ \\
\hline & & F: 0.18 & & F: $40 \%$ & $\begin{array}{l}\text { MS: } 15 \% \\
\text { SC: } 75 \%\end{array}$ & \\
\hline
\end{tabular}

$S B$ skull base, $M S$ mobile spine, $S C$ sacrum/coccyx, $N R$ not reported

most strikingly for England and the USA; whereas the English study showed that the sacrum or coccyx was affected in $45 \%$ of cases and the skull base in $26 \%$ of the cases, the US study reported these sites were affected in $29 \%$ and $32 \%$ of cases, respectively $[10,11]$. The mobile spine was found to be affected in $15-33 \%$ of cases $[10,11$, $13,15]$. The US study by McMaster et al. reported incidence rates of chordoma in blacks to be only one-fourth of that in whites. However, as reported by the authors, the 
number of patients on which this observation is based was too limited to draw definitive conclusions [10].

\section{Prognosis}

\section{Literature search}

The literature search identified 1754 citations, of which 1187 remained when duplicates were removed. Further selection based on title, abstract, and full text resulted in 22 papers that met all criteria to be considered for further analysis [17-38]. After reference screening and citation tracking, two more papers meeting all inclusion criteria were found $[39,40]$. Screening reference lists of (systematic) reviews and meta-analyses did not result in the identification of any new papers. As a result, a total number of 24 papers were included (Fig. 2). An overview of study characteristics is provided in Table 4 .

\section{Risk of bias assessment}

After consulting the third reviewer, consensus about risk of bias score was reached in all cases. Sixteen papers were considered to have low risk of bias (scores 5-6 out of 6; Table 5). The remaining seven studies with higher risk of bias failed to pay appropriate attention to potential confounding variables and adequate statistical analysis [27, 28, 31-35].

It should be noted that all studies were case series and as such should not be considered high-quality evidence, despite their reasonable risk of bias scores.

\section{Overview}

All papers were published in English between 1993 and 2016, and the majority were published between 2009 and 2016 [17-19, 21-26, 32-35, 37-40]. The number of patients varied substantially between studies, ranging from 23 to 962 patients. Patient age in studies concerning chordoma of the skull base was typically in the forties, whereas patient

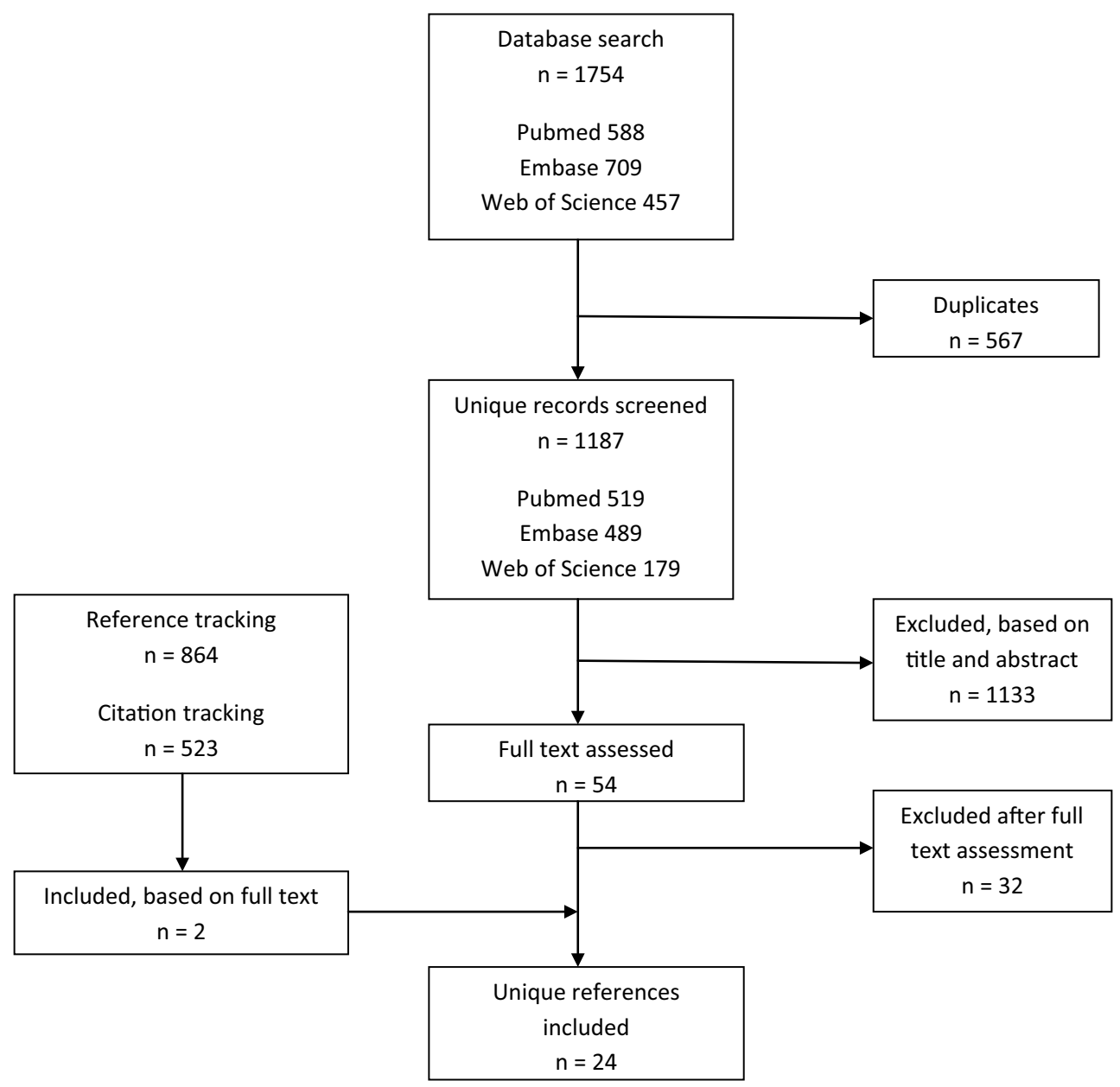

Fig. 2 Flowchart-prognosis 


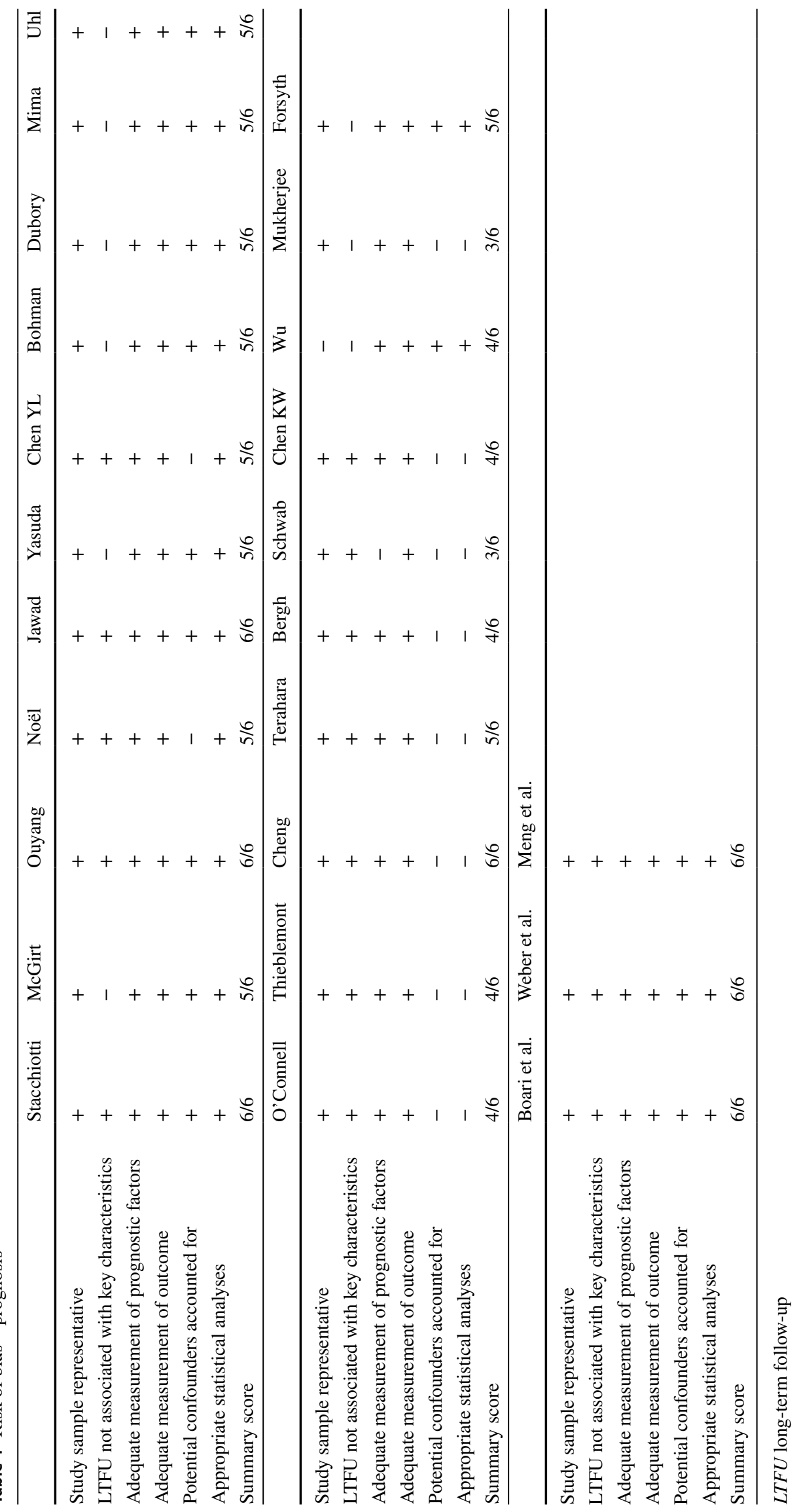


Table 5 Characteristics-prognosis

\begin{tabular}{|c|c|c|c|c|c|c|}
\hline Authors & $\begin{array}{l}\text { Year of publi- } \\
\text { cation }\end{array}$ & Study quality & $\begin{array}{l}\text { Number of } \\
\text { patients }\end{array}$ & Age & Sex & Tumour location \\
\hline Bohman & 2014 & $5 / 6$ & 416 & $\begin{array}{l}<18(9 \%) \\
18-39(28 \%) \\
40-59(34 \%) \\
60-84(28 \%) \\
\geq 85(1 \%)\end{array}$ & $\begin{array}{l}\text { M: } 56 \% \\
\text { F: } 44 \%\end{array}$ & SB: $100 \%$ \\
\hline Uhl & 2014 & $5 / 6$ & 155 & Median: 48 (range 15-85) & $\begin{array}{l}\text { M: } 49 \% \\
\text { F: } 51 \%\end{array}$ & SB: $100 \%$ \\
\hline Weber & 2016 & $6 / 6$ & 151 & Mean: 43.3 & $\begin{array}{l}\text { M: } 57 \% \\
\text { F: } 43 \%\end{array}$ & SB: $100 \%$ \\
\hline Terahara & 1999 & $4 / 6$ & 115 & Median: 45 (range 19-80) & $\begin{array}{l}\text { M: } 57.4 \% \\
\text { F: } 42.6 \%\end{array}$ & SB: $100 \%$ \\
\hline $\mathrm{Wu}$ & 2010 & $4 / 6$ & 79 & Mean $35.6^{\mathrm{a}}$ (range $\left.7-65\right)$ & $\begin{array}{l}\text { M: } 56.6 \% \\
\text { F: } 43.4 \%^{\mathrm{a}}\end{array}$ & SB: $100 \%$ \\
\hline Ouyang & 2014 & $6 / 6$ & $77^{\mathrm{b}}$ & Mean: 42.5 & $\begin{array}{l}\text { M: } 65 \% \\
\text { F: } 35 \%\end{array}$ & SB: $100 \%$ \\
\hline O'Connell & 1994 & $4 / 6$ & 62 & Median M: 36 F: 37 & $\begin{array}{l}\text { M: } 53.2 \% \\
\text { F: } 46.8 \%\end{array}$ & SB: $100 \%$ \\
\hline Forsyth & 1993 & $1 / 6$ & 51 & Median: 46 & $\begin{array}{l}\text { M: } 55 \% \\
\text { F: } 45 \%\end{array}$ & SB: $100 \%$ \\
\hline Boari & 2016 & $6 / 6$ & 45 & Mean: 46.7 & $\begin{array}{l}\text { M: } 67 \% \\
\text { F: } 33 \%\end{array}$ & SB: $100 \%$ \\
\hline Noël & 2004 & $5 / 6$ & $90^{\mathrm{c}}$ & Mean: 49 (range 10-85) & $\begin{array}{l}\text { M: } 57.8 \% \\
\text { F: } 42.2 \%\end{array}$ & $\begin{array}{l}\text { SB: } 93.3 \% \\
\text { CS: } 6.7 \%\end{array}$ \\
\hline Yasuda & 2012 & $5 / 6$ & 40 & Mean: 45.1 (range 11-68) & $\begin{array}{l}\text { M: } 70 \% \\
\text { F: } 30 \%\end{array}$ & $\begin{array}{l}\text { SB: } 42.5 \% \\
\text { CVJ: } 32.5 \% \\
\text { CS: } 25 \%\end{array}$ \\
\hline Cheng & 1999 & $4 / 6$ & 23 & Mean: 55 (range 28-85) & $\begin{array}{l}\text { M: } 60.9 \% \\
\text { F: } 39.1 \%\end{array}$ & $\begin{array}{l}\text { LS: } 17.4 \% \\
\text { SC: } 82.6 \%\end{array}$ \\
\hline Schwab & 2009 & $4 / 6$ & 42 & NR & $\begin{array}{l}\text { M: } 70 \% \\
\text { F: } 30 \%\end{array}$ & S: $100 \%$ \\
\hline Chen KW & 2010 & $4 / 6$ & 36 & Mean: 51.5 (range 18-77) & $\begin{array}{l}\text { M: } 56 \% \\
\text { F: } 44 \%)\end{array}$ & S: $100 \%$ \\
\hline Dubory & 2014 & $5 / 6$ & 29 & Mean: 53.3 (range 25-75) & $\begin{array}{l}\text { M: } 59 \% \\
\text { F: } 41 \%\end{array}$ & S: $100 \%$ \\
\hline Mima & 2014 & $5 / 6$ & 23 & Median: 72 (range 35-84) & $\begin{array}{l}\text { M: } 65 \% \\
\text { F: } 35 \%\end{array}$ & S: $100 \%$ \\
\hline Mukherjee & 2011 & $4 / 6$ & 414 & Mean: 59.9 & $\begin{array}{l}\text { M: } 62.8 \% \\
\text { F: } 37.2 \%\end{array}$ & $\begin{array}{l}\text { MS: } 47.1 \% \\
\text { SC: } 52.9 \%\end{array}$ \\
\hline Stacchiotti & 2010 & $6 / 6$ & 138 & Median: 59 (range 50-65) & $\begin{array}{l}\text { M: } 65.9 \% \\
\text { F: } 34.1 \%\end{array}$ & $\begin{array}{l}\text { CTS: } 6.5 \% \\
\text { LS: } 15.2 \% \\
\text { S: } 78.3 \%\end{array}$ \\
\hline McGirt & 2011 & $6 / 6$ & 114 & Mean: 57.5 & $\begin{array}{l}\text { M: } 63 \% \\
\text { F: } 37 \%\end{array}$ & $\begin{array}{l}\text { MS: } 42 \% \\
\text { SC } 58 \%\end{array}$ \\
\hline Bergh & 2000 & $4 / 6$ & 39 & Mean: 55 (range 25-81) & $\begin{array}{l}\text { M: } 44 \% \\
\text { F: } 56 \%\end{array}$ & $\begin{array}{l}\text { CS: } 12.8 \% \\
\text { TS: } 2.5 \% \\
\text { LS: } 7.5 \% \\
\text { S: } 77.2 \%\end{array}$ \\
\hline
\end{tabular}


Table 5 (continued)

\begin{tabular}{|c|c|c|c|c|c|c|}
\hline Authors & $\begin{array}{l}\text { Year of publi- } \\
\text { cation }\end{array}$ & Study quality & $\begin{array}{l}\text { Number of } \\
\text { patients }\end{array}$ & Age & Sex & Tumour location \\
\hline Chen YL & 2013 & $5 / 6$ & 24 & Median: 69.5 & $\begin{array}{l}\text { M: } 54 \% \\
\text { F: } 46 \%\end{array}$ & $\begin{array}{l}\text { CS: } 8 \% \\
\text { TS: } 4 \% \\
\text { LS: } 8 \% \\
\text { S: } 80 \%\end{array}$ \\
\hline Jawad & 2010 & $5 / 6$ & 962 & $\begin{array}{l}0-29(12.2 \%) \\
29-59(42.6 \%) \\
>59(45.2 \%)\end{array}$ & $\begin{array}{l}\text { M: } 58.4 \% \\
\text { F: } 41.6 \%\end{array}$ & $\begin{array}{l}\text { SB: } 42.1 \% \\
\text { MS and others: }(28.4 \%) \\
\text { S: } 29.5 \%\end{array}$ \\
\hline Thieblemont & 1995 & $4 / 6$ & 26 & Median: 50 (range 22-73) & $\begin{array}{l}\text { M: } 57.7 \% \\
\text { F: } 42.3 \%)\end{array}$ & $\begin{array}{l}\text { SB: } 30.8 \% \\
\text { CS: } 15.4 \% \\
\text { TS: } 3.8 \% \\
\text { LS: } 11.5 \% \\
\text { S: } 38.5 \%\end{array}$ \\
\hline Meng & 2015 & $6 / 6$ & 153 & Mean: 54.5 (range 15-81) & $\begin{array}{l}\text { M: } 65 \% \\
\text { F: } 35 \%\end{array}$ & $\begin{array}{l}\text { C1-C2: } 12 \% \\
\text { C3-L5: } 26 \% \\
\text { Sacrum: } 62 \%\end{array}$ \\
\hline
\end{tabular}

${ }^{a}$ Reported for 106 patients-only 79 were analysed, $S C$ sacrum/coccyx, $N R$ not reported

${ }^{\mathrm{b}}$ Follow-up information for 66 patients, $S B$ skull base, $C T S$ cervicothoracic spine, $C V J$ craniovertebral junction

c64 chordomas, $C S$ cervical spine, $L S$ lumbar spine, $T S$ thoracic spine

age in studies examining the entire vertebral column and skull base combined was commonly in the fifties. The latter matched the findings of the epidemiological papers. Again, a clear male predominance for the occurrence of chordoma was observed. Studies examining both the skull base and entire vertebral column found anatomical distributions slightly different from those reported in the epidemiological studies from England and the USA, with especially the skull base being more frequently affected in the prognostic study by Jawad and Scully [21]. Follow-up ranged from 0 to 356 months. Table 6 provides an overview of the extracted data. Patient characteristics and methods differed significantly; hence, no pooled analyses could be performed.

Nine papers reported exclusively on the skull base [19, 24, 27, 30, 34, 36-39]. All patients in these studies were treated by surgery, radiation therapy, chemotherapy, or a combination of these. Significant adverse prognostic factors for PFS were non-total resection, dedifferentiated histological subtype, age $>40$ years, history of prior treatment, gross tumour volume $>25 \mathrm{cc}$, tight tumour adherence to a vital structure, rhinopharynx invasion, optic apparatus compression, brainstem compression, and no or lower dose of radiation therapy. Female gender and male gender were both reported as significant adverse prognostic factors for PFS $[27,30]$. Significant adverse prognostic factors for OS were non-total resection, dedifferentiated histological subtype, age $>40$ years, a history of prior treatment, tumour size $\geq 4 \mathrm{~cm}$, gross tumour volume $>25 \mathrm{cc}$, rhinopharynx invasion, optic apparatus compression, brainstem compression, and again no or a lower dose of radiation therapy and female gender.

Seven studies reported solely on the vertebral column $[17,18,23,29,31,35,40]$. All patients were treated by surgery, radiation therapy, or a combination of both. Significant adverse prognostic factors for PFS were a relatively bigger tumour, dedifferentiated subtype, preoperative Frankel scores $\mathrm{A}-\mathrm{C}$, older age, inadequate surgical margins, non-en bloc resection (as compared to en bloc resection), a history of prior treatment or an invasive diagnostic procedure performed at another hospital, and a tumour localised in $\mathrm{C} 1-\mathrm{C} 2$ or S1-S5. The following significant adverse prognostic factors for OS were mentioned: a relatively bigger tumour, older age, earlier year of diagnosis, prior treatment, Enneking stage II-III, lower tumour location, increasing extent of tumour invasion, presence of distant metastasis, tumour localised in $\mathrm{C} 1$ or C2 or S1-S5, Karnofsky performance score $<80$, no preoperative tumour embolisation, complication after surgery, inadequate surgical margins, and non-en bloc resection (as compared to en bloc resection).

Four studies focused on the sacrum [25, 26, 32, 33]. Patients were treated by tumour embolisation, (cryo)surgery, radiation therapy, chemotherapy, or a combination of these. Adverse prognostic factors reported to be of significant influence on PFS were female gender, a history of prior resection, and surrounding muscle invasion. Significant adverse prognostic factors for overall survival were local recurrence, presence of metastasis, a history of prior resection, and a high-grade lesion. 


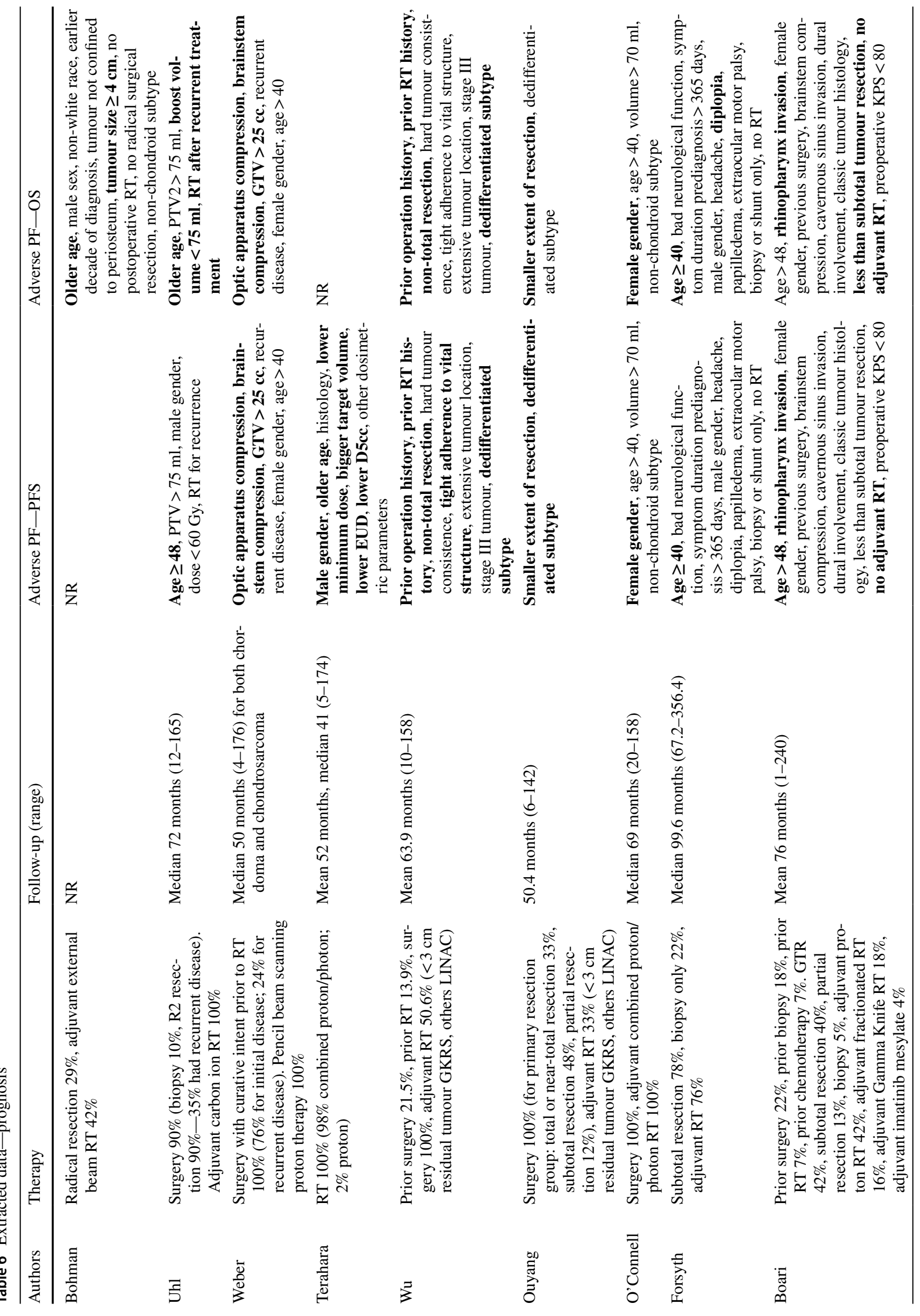




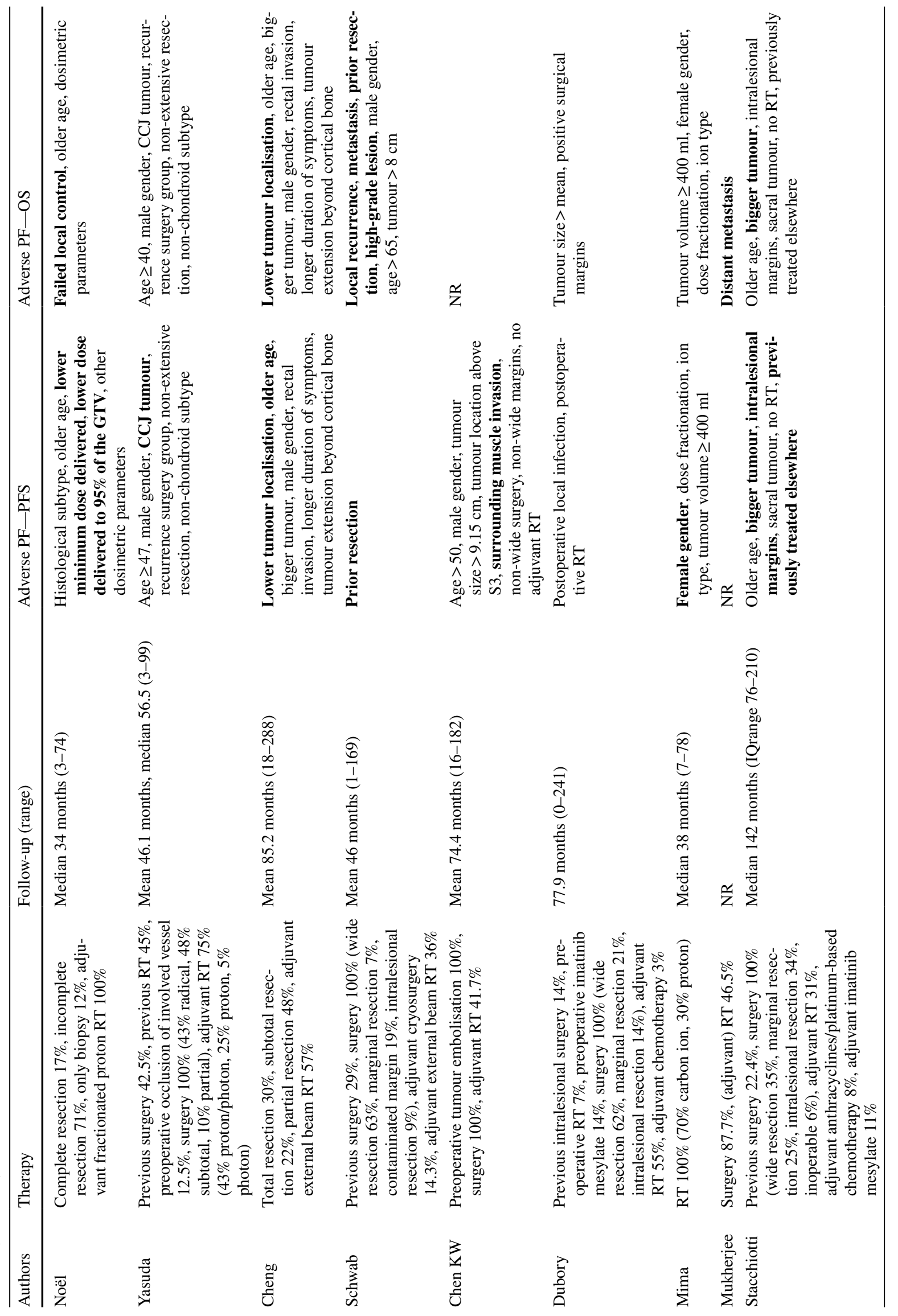




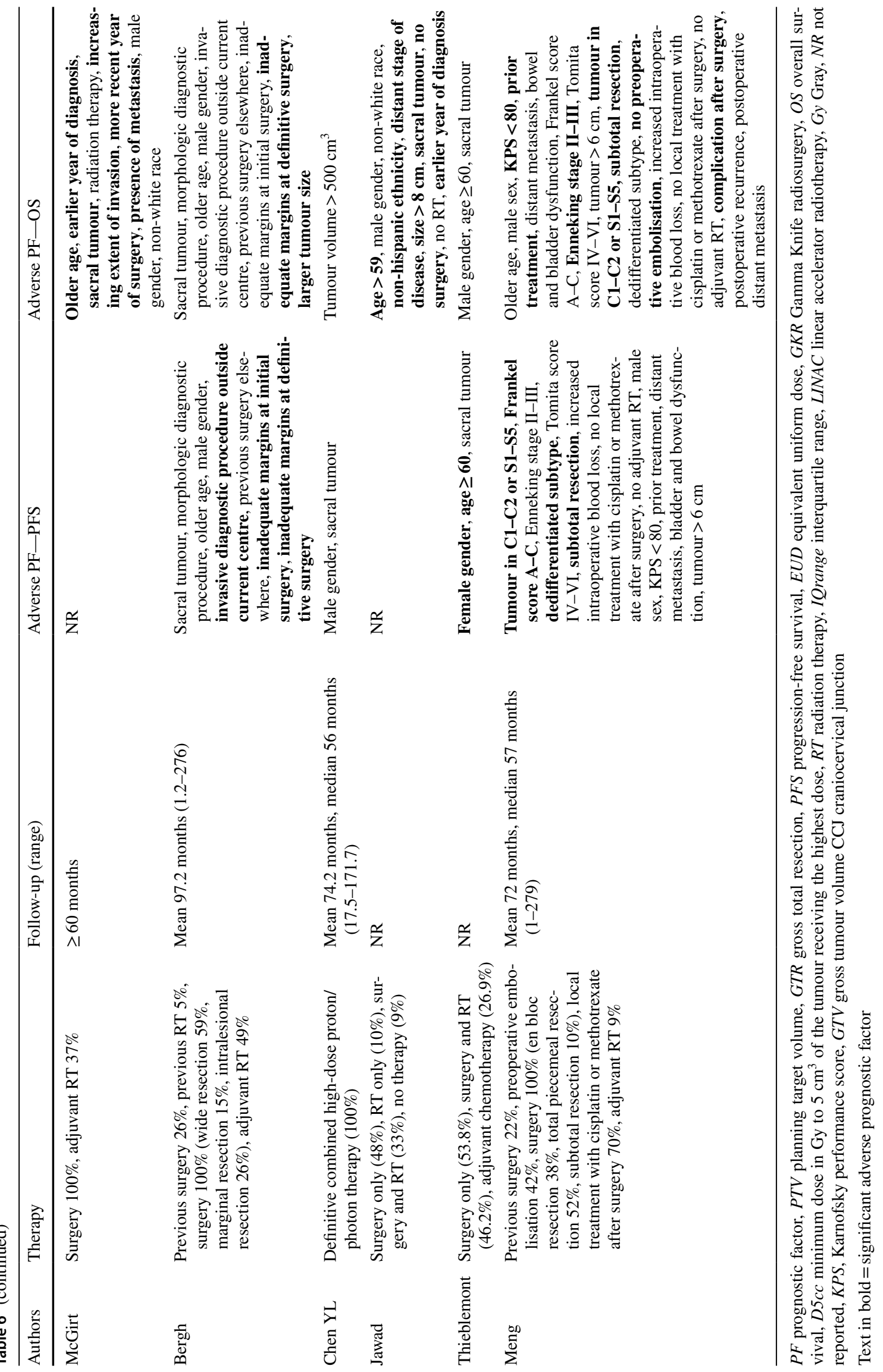


The remaining four studies reported on combinations of the skull base and various areas of the vertebral column $[20-22,28]$. The patients described were treated by tumour biopsy, tumour embolisation, surgery, radiation therapy, and chemotherapy, and a small number of patients received no treatment at all. Several significant adverse prognostic factors for PFS were reported: a lower dose of radiation therapy, a tumour localised at the craniocervical junction, female gender, and age $\geq 60$ years. Significant adverse prognostic factors for OS were failed local control, age $\geq 59$ years, non-Hispanic ethnicity, presence of metastasis, tumour size $>8 \mathrm{~cm}$, a sacral tumour, no surgical therapy, and earlier year of diagnosis.

\section{Discussion}

Our findings show that incidence rates vary notably between countries. The incidence rate of approximately 0.8 per million persons per year reported for the US studies making use of the SEER registry is often cited in papers on chordoma, but the European and Taiwanese studies show different results, with incidence rates ranging from 0.18 to 0.52 per million persons per year [10-16, 41, 42]. Quality of case collection does not seem to be an explanation for these differences, as can be concluded from analysis of the registries indicating they perform similarly well [43-46]. Furthermore, all studies were population-based cohort studies which were demonstrated to have low risk of bias, making study design an unlikely explanation. A possible explanation is the difference in genetic background between the European, the US, and the Taiwanese populations. Indeed, as is shown by the results of the study by McMaster et al. [10], incidence rates of chordoma are likely to vary between races. Yet another explanation possibly contributing to the discrepancy in incidence rates and the lower percentage of patients affected by skull base chordoma in European countries and Taiwan when compared to the USA is that in the former countries for some period of time skull base chordoma might have been regularly mistaken for skull base chondrosarcoma and got misclassified as such [47]. Finally, it is unfortunate that the paper by Stiller et al. [16] does not more precisely specify the incidence rate that was found for the entire European population and instead only reports it was less than 1 per million persons per year.

Both the epidemiological and prognostic papers showed a clear male predominance for the occurrence of chordoma. The prognostic studies also showed that patients affected by skull base chordoma were generally diagnosed at a younger age than those affected by chordoma of the vertebral column. This is likely due to the limited amount of space the tumour can occupy before causing symptoms by compressing vulnerable structures in the direct vicinity of the skull base.
An evident limitation of the prognostic studies included in this review is the fact that they were all case series. Risk of bias assessment demonstrated they were good-quality case series, but the inherent weaknesses of this study design nevertheless result in low quality of evidence. Because different patient groups and treatment strategies were examined using different methodologies, it was not possible to report prognostic factors for chordoma patients in general. Treatment ranged from biopsy only, embolisation, surgery, cryosurgery, radiation therapy, systemic therapy, and combinations of these, to no treatment at all. However, some prognostic factors were commonly mentioned for different tumour locations and thus might be of influence on prognosis of most chordoma patients. Examples include inadequate surgical margins, older age, no adjuvant radiation therapy or lower dose of radiation therapy, and bigger tumour size, which all were of negative influence on both PFS and OS. One of three papers describing preoperative embolisation found an adverse prognostic effect for patients not undergoing preoperative embolisation [40]. Four papers described patients (also) undergoing systemic therapy, but none of these papers found systemic therapy to be of significant effect on prognosis $[17,25,28,37]$. The aforementioned prognostic factors were of influence on PFS (including distant metastasis) and likely through this effect also affected OS, since local control and distant metastasis were found to be of prognostic importance for OS in multiple papers [18, 20, 21, 32, 35, 40]. The paper by Terahara et al. [30] was the only one reporting male gender as an adverse prognostic factor for PFS. Three other studies reported instead that female gender was an adverse prognostic factor for PFS, and one study reported that female gender had an adverse prognostic effect on OS [26-28]. The studies by McGirt et al. [18] and Jawad and Scully [21] reported patients with sacral tumours had worse OS than patients with chordoma above the sacrum. Cheng et al. [29] confirmed this finding and additionally showed that sacral tumours are of adverse prognostic influence on PFS. This might be explained by the fact that sacral tumours often grow very large before causing symptoms and consequently are often diagnosed at a later stage. This delay in diagnosis theoretically offers the tumour opportunity to accumulate more harmful mutations, which subsequently allow it to behave in a more malignant manner.

An important difference in treatment of skull base chordoma and chordoma of the spine is the fact that skull base chordoma cannot be resected en bloc. It is generally accepted that total resection should be aimed for whenever possible.

The importance of en bloc resection of spinal chordoma, when possible, is reflected in the paper by Meng et al. [40], which shows that en bloc resection results in better PFS and OS when compared to piecemeal total resection. This finding is not supported by the three papers focusing solely on surgery of sacral chordoma, but this may be due to smaller sample 
size and the above-mentioned theory concerning mutations in sacral chordoma [25, 32, 33]. However, intralesional resection of sacral chordoma followed by radiation therapy might have better outcome compared to extralesional resection alone [48]. This finding stresses the importance of radiation therapy, the technique of which is rapidly improving. Proton radiation therapy is becoming more widely available, and the long-term results of carbon ion radiation are becoming increasingly clear. These techniques allow high doses of radiation to be more safely delivered to the tumour. The papers by Terahara et al. [30] and Mima et al. [26] focus on radiation therapy, and Mima reports promising results of primary sacral chordoma solely treated by carbon ion radiation.

In conclusion, this is the first systematic review of the epidemiology of chordoma and of prognostic factors affecting PFS and OS. Our findings show that incidence rate and tumour location vary between countries. Several adverse prognostic factors were identified, albeit in studies of limited quality and with varying treatment strategies. Hence, we suggest-as has recently been proposed by the global chordoma consensus group-future research should focus on planning carefully designed prospective studies [49]. Based on such studies, physicians can better inform their patients and adequately adapt treatment plans.

Acknowledgements We thank Jan W. Schoones, health care librarian specialised in literature research at Leiden University Medical Center, for his help with the search strategy and literature search. We also thank the Chordoma Foundation for giving us the opportunity to share our results with researchers and clinicians and for stimulating us to continue our research in this field.

\section{Compliance with ethical standard}

Conflict of interest The authors declare that they have no conflict of interests.

Open Access This article is distributed under the terms of the Creative Commons Attribution 4.0 International License (http://creativeco mmons.org/licenses/by/4.0/), which permits unrestricted use, distribution, and reproduction in any medium, provided you give appropriate credit to the original author(s) and the source, provide a link to the Creative Commons license, and indicate if changes were made.

\section{References}

1. Murphey M, Andrews C, Flemming D, Temple H, Smith W, Smirniotopoulos J (1996) From the archives of the AFIP. Primary tumors of the spine: radiologic pathologic correlation. Radiographics 16(5):1131-1158

2. Boriani S, Bandiera S, Biagini R, Bacchini P, Boriani L, Cappuccio M, Chevalley F, Gasbarrini A, Picci P, Weinstein JN (2006) Chordoma of the mobile spine: fifty years of experience. Spine 31(4):493

3. Virchow R (1857) Untersuchungen über die Entwicklung des Schädelgrundes im gesunden und krankhaften Zustande und über den Einfluss derselben auf Schädelform, Gesichtsbildung und Gehirnbau. Reimer, Berlin

4. Müller H (1858) Ueber das Vorkommen von Resten der Chorda dorsalis bei Menschen nach der Geburt, und über ihr Verhältnis zu den Gallertgeschwulsten der Clivus. Ztsch f rationelle Med 2:202-229

5. Urban J, Roberts S, Ralphs J (2000) The nucleus of the intervertebral disc from development to degeneration. Am Zool 40:53-61

6. Amer H, Hameed M (2010) Intraosseous benign notochordal cell tumor. Arch Pathol Lab Med 134:283-288

7. Yang X, Ng D, Alcorta D, Liebsch N, Sheridan E, Li S, Goldstein A, Parry D, Kelley M (2009) T (brachyury) gene duplication confers major susceptibility to familial chordoma. Nat Genet 41(11):1176-1178

8. Hoy D, Brooks P, Woolf A, Blyth F, March L, Bain C, Baker P, Smith E, Buchbinder R (2012) Assessing risk of bias in prevalence studies: modification of an existing tool and evidence of interrater agreement. J Clin Epidemiol 65:934-939

9. Hayden J, Côté P, Bombardier C (2006) Evaluation of the quality of prognosis studies in systematic reviews. Ann Intern Med 144:427-437

10. McMaster M, Goldstein A, Bromley C, Ishibe N, Parry D (2001) Chordoma: incidence and survival patterns in the United States, 1973-1995. Cancer Causes Control 12(1):1-11

11. Whelan J, McTiernan A, Cooper N, Wong Y, Francis M, Vernon S, Strauss S (2012) Incidence and survival of malignant bone sarcomas in England 1979-2007. Int J Cancer 131(4):508-517

12. Smoll N, Gautschi O, Radovanovic I, Schaller K, Weber D (2013) Incidence and relative survival of chordomas: the standardized mortality ratio and the impact of chordomas on a population. Cancer 119(11):2029-2037

13. Eriksson B, Gunterberg B, Kindblom L (1981) Chordoma. A clinicopathologic and prognostic study of a Swedish national series. Acta Orthop Scand 52(1):49-58

14. Hung G, Horng J, Yen H, Yen C, Chen W, Chen P, Wu H, Chiou H (2014) Incidence patterns of primary bone cancer in Taiwan (20032010): a population-based study. Ann Surg Oncol 21(8):2490-2498

15. Paavolainen P, Teppo L (1976) Chordoma in Finland. Acta Orthop Scand 47(1):46-51

16. Stiller C, Trama A, Serraino D, Rossi S, Navarro C, Chirlaque M, Casali P (2013) RARECARE working group. Descriptive epidemiology of sarcomas in Europe: report from the RARECARE project. Eur J Cancer 49(3):684-695

17. Stacchiotti S, Casali P, Lo Vullo S, Mariani L, Palassini E, Mercuri M, Alberghini M, Pilotti S, Zanella L, Gronchi A, Picci P (2010) Chordoma of the mobile spine and sacrum: a retrospective analysis of a series of patients surgically treated at two referral centers. Ann Surg Oncol 17(1):211-219

18. McGirt M, Gokaslan Z, Chaichana K (2011) Preoperative grading scale to predict survival in patients undergoing resection of malignant primary osseous spinal neoplasms. Spine J 11(3):190-196

19. Ouyang T, Zhang N, Zhang Y, Jiao J, Ren J, Huang T, Chen J (2014) Clinical characteristics, immunohistochemistry, and outcomes of 77 patients with skull base chordomas. World Neurosurg 81(5-6):790-797

20. Noël G, Feuvret L, Ferrand R, Boisserie G, Mazeron J, Habrand $\mathrm{J}$ (2004) Radiotherapeutic factors in the management of cervical-basal chordomas and chondrosarcomas. Neurosurgery 55(6):1252-1260

21. Jawad M, Scully S (2010) Surgery significantly improves survival in patients with chordoma. Spine 35(1):117-123

22. Yasuda M, Bresson D, Chibbaro S, Cornelius J, Polivka M, Feuvret L, Takayasu M, George B (2012) Chordomas of the skull base and cervical spine: clinical outcomes associated with a 
multimodal surgical resection combined with proton-beam radiation in 40 patients. Neurosurg Rev 35(2):171-182

23. Chen Y, Liebsch N, Kobayashi W, Goldberg S, Kirsch D, Calkins G, Childs S, Schwab J, Hornicek F, DeLaney T (2013) Definitive high-dose photon/proton radiotherapy for unresected mobile spine and sacral chordomas. Spine 38(15):E930-E936

24. Bohman L, Koch M, Bailey R, Alonso-Basanta M, Lee J (2014) Skull base chordoma and chondrosarcoma: influence of clinical and demographic factors on prognosis: a SEER analysis. World Neurosurg 82(5):806-814

25. Dubory A, Missenard G, Lambert B, Court C (2014) "En bloc" resection of sacral chordomas by combined anterior and posterior surgical approach: a monocentric retrospective review about 29 cases. Eur Spine J 23(9):1940-1948

26. Mima M, Demizu Y, Jin D, Hashimoto N, Takagi M, Terashima K, Fujii O, Niwa Y, Akagi T, Daimon T, Hishikawa Y, Abe M, Murakami M, Sasaki R, Fuwa N (2014) Particle therapy using carbon ions or protons as a definitive therapy for patients with primary sacral chordoma. Br J Radiol 87(1033):20130512

27. O'Connell J, Renard L, Liebsch N, Efird J, Munzenrider J, Rosenberg A (1994) Base of skull chordoma. A correlative study of histologic and clinical features of 62 cases. Cancer 74(8):2261-2267

28. Thieblemont C, Biron P, Rocher F, Bouhour D, Bobin JY, Gérard JP, Blay JY (1995) Prognostic factors in chordoma: role of postoperative radiotherapy. Eur J Cancer 31A(13-14):2255-2259

29. Cheng E, Ozerdemoglu R, Transfeldt E, Thompson R Jr (1999) Lumbosacral chordoma. Prognostic factors and treatment. Spine 24(16):1639-1645

30. Terahara A, Niemierko A, Goitein M, Finkelstein D, Hug E, Liebsch N, O'Farrell D, Lyons S, Munzenrider J (1999) Analysis of the relationship between tumor dose inhomogeneity and local control in patients with skull base chordoma. Int J Radiat Oncol Biol Phys 45(2):351-358

31. Bergh P, Kindblom L, Gunterberg B, Remotti F, Ryd W, MeisKindblom J (2000) Prognostic factors in chordoma of the sacrum and mobile spine: a study of 39 patients. Cancer 88(9):2122-2134

32. Schwab J, Healey J, Rose P, Casas-Ganem J, Boland P (2009) The surgical management of sacral chordomas. Spine 34(24):2700-2704

33. Chen K, Yang H, Lu J, Liu J, Chen X (2010) Prognostic factors of sacral chordoma after surgical therapy: a study of 36 patients. Spinal Cord 48(2):166-171

34. Wu Z, Zhang J, Zhang L, Jia G, Tang J, Wang L, Wang Z (2010) Prognostic factors for long-term outcome of patients with surgical resection of skull base chordomas-106 cases review in one institution. Neurosurg Rev 33(4):451-456

35. Mukherjee D, Chaichana K, Adogwa O, Gokaslan Z, Aaronson O, Cheng J, McGirt M (2011) Association of extent of local tumor invasion and survival in patients with malignant primary osseous spinal neoplasms from the surveillance, epidemiology, and end results (SEER) database. World Neurosurg 76(6):580-585

36. Forsyth P, Cascino T, Shaw E, Scheithauer B, O'Fallon J, Dozier J, Piepgras D (1993) Intracranial chordomas: a clinicopathological and prognostic study of 51 cases. J Neurosurg 78(5):741-747

37. Boari N, Gagliardi F, Cavalli A, Gemma M, Ferrari L, Riva P, Mortini P (2016) Skull base chordomas: clinical outcome in a consecutive series of 45 patients with long- term follow-up and evaluation of clinical and biological prognostic factors. J Neurosurg 125:450-460

38. Weber D, Malyapa R, Albertini F, Bolsi A, Kliebsch U, Walser M, Pica A, Combescure C, Lomax A, Schneider R (2016) Long term outcomes of patients with skull-base low-grade chondrosarcoma and chordoma patients treated with pencil beam scanning proton therapy. Radiother Oncol 120:169-174

39. Uhl M, Mattke M, Welzel T, Roeder F, Oelmann J, Habl G, Jensen A, Ellerbrock M, Jäkel O, Haberer T, Herfarth K, Debus J (2014) Highly effective treatment of skull base chordoma with carbon ion irradiation using a raster scan technique in 155 patients: first long-term results. Cancer 120(21):3410-3417

40. Meng T, Yin H, Li B, Li Z, Xu W, Zhou W, Cheng M, Wang J, Zhou L, Yang X, Liu T, Yan W, Song D, Xiao J (2015) Clinical features and prognostic factors of patients with chordoma in the spine: a retrospective analysis of 153 patients in a single center. Neuro Oncol 7(5):725-732

41. Walcott B, Nahed B, Mohyeldin A, Coumans J, Kahle K, Ferreira M (2012) Chordoma: current concepts, management, and future directions. Lancet Oncol 13(2):e69-e76

42. Sciubba D, Chi J, Rhines L, Gokaslan Z (2008) Chordoma of the spinal column. Neurosurg Clin N Am 19(1):5-15

43. National Cancer Intelligence Network (2008) The completeness of bone sarcoma data in the National Cancer Data Repository. Tumours diagnosed between 2006 and 2008. http://www.ncin.org. uk/publications/reports/. Accessed 30 Nov 2015

44. Rossi S, Baili P, Capocaccia R, Caldora M, Carrani E, Minicozzi P, Pierannunzio D, Santaquilani M, Trama A, Allemani C, Belot A, Buzzoni C, Lorez M, De Angelis R (2015) EUROCARE-5 working group. The EUROCARE-5 study on cancer survival in Europe 1999-2007: database, quality checks and statistical analysis methods. Eur J Cancer. https://doi.org/10.1016/j. ejca.2015.08.001. (Epub ahead of print)

45. Taiwan Cancer Registry annual report. Taiwan: health promotion administration, ministry of health and welfare. http://www.hpa. gov.tw/bhpnet/web/stat/statisticsshow.aspx?no=200911300001. Accessed 30 Nov 2015

46. Zippin C, Lum D, Hankey B (1995) Completeness of hospital cancer case reporting from the SEER Program of the National Cancer Institute. Cancer 76(11):2343-2350

47. Rosenberg A, Nielsen G, Keel S, Renard L, Fitzek M, Munzenrider J, Liebsch N (1999) Chondrosarcoma of the base of the skull: a clinicopathologic study of 200 cases with emphasis on its distinction from chordoma. Am J Surg Pathol 23(11):1370-1378

48. Moojen W, Vleggeert-Lankamp C, Krol A, Dijkstra S (2011) Long-term results: adjuvant radiotherapy in en bloc resection of sacrococcygeal chordoma is advisable. Spine (Phila Pa 1976) 36(10):E656-E661

49. Stacchiotti S, Sommer J (2015) Chordoma Global Consensus Group. Building a global consensus approach to chordoma: a position paper from the medical and patient community. Lancet Oncol 16(2):e71-e83 


\section{Affiliations}

S. H. Bakker ${ }^{1}$ - W. C. H. Jacobs ${ }^{1}$ - W. Pondaag ${ }^{1}$ - H. Gelderblom ${ }^{2}$ - R. A. Nout ${ }^{3}$ · P. D. S. Dijkstra ${ }^{4}$ - W. C. Peul ${ }^{1}$. C. L. A. Vleggeert-Lankamp ${ }^{1}$

$\triangle$ S. H. Bakker s.h.bakker@lumc.nl

1 Department of Neurosurgery, Leiden University Medical Center, P.O. Box 9600, 2300 RC Leiden, The Netherlands

2 Department of Clinical Oncology, Leiden University Medical Center, Leiden, The Netherlands
3 Departmant of Radiation Oncology, Leiden University Medical Center, Leiden, The Netherlands

4 Department of Orthopedic Surgery, Leiden University Medical Center, Leiden, The Netherlands 